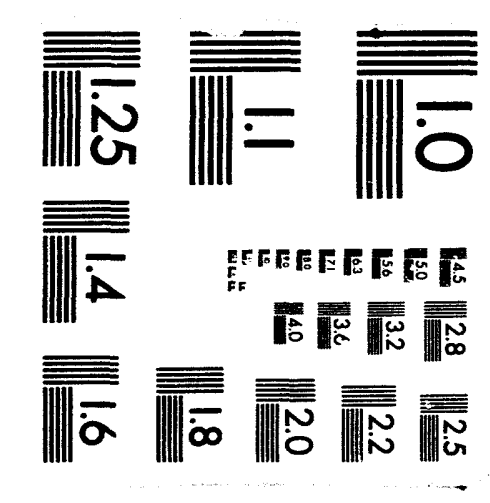



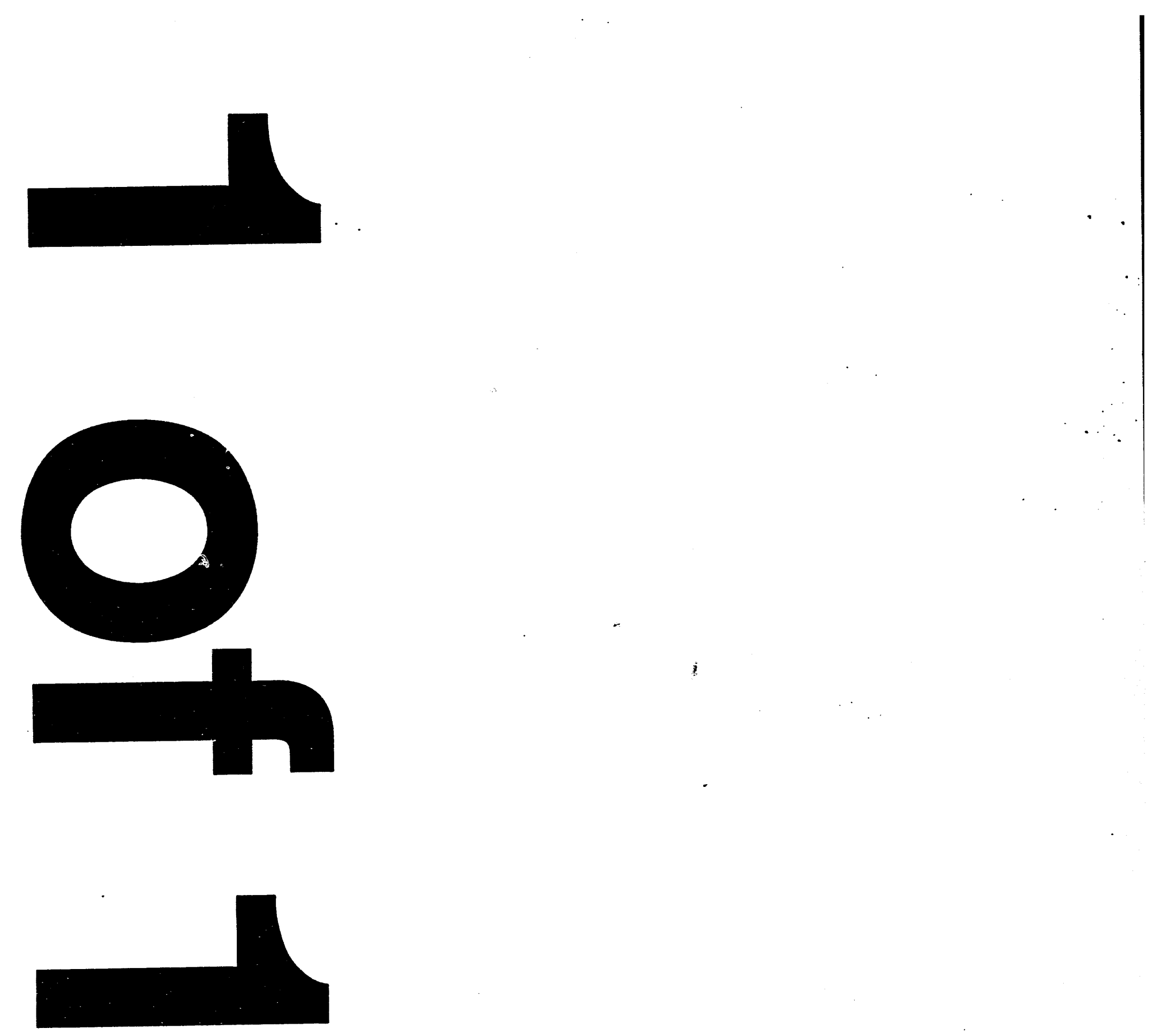


\title{
ANALYSIS OF FEMTOGRAM-SIZED PLUTONIUM SAMPLES
}

\author{
D. H. Smith, H. S. McKown, D. T. Bostick, R. M. Coleman
}

D. C. Duckworth, and R. L. McPherson

Chemical and Analytical Sciences Division

Date published January 1994

NOTICE This document contains information of a proliminary nature. It is subject to revision or correction and therefore does not represent a final report.

\footnotetext{
OAK RIDGE NATIONAL LABORATORY

Oak Ridge, Tennessee 37831 managed by MARTIN MARIETTA ENERGY SYSTEMS, INC. for the U.S. DEPARTMENT OF ENERGY under Contract No. DE-AC05-84OR21400
} 
TABLE OF CONTENTS

PAGE

ABSTRACT

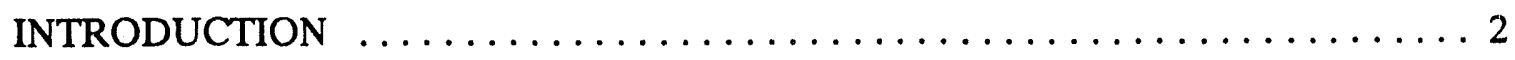

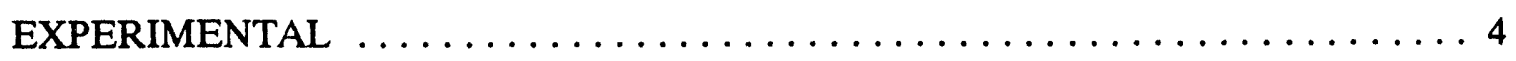

RESULTS AND DISCUSSION $\ldots \ldots \ldots \ldots \ldots \ldots \ldots \ldots \ldots \ldots \ldots$

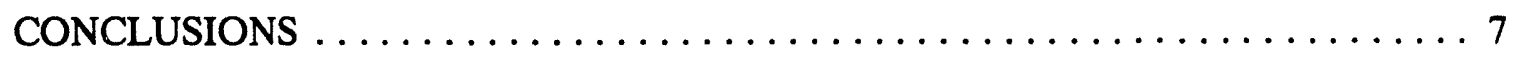

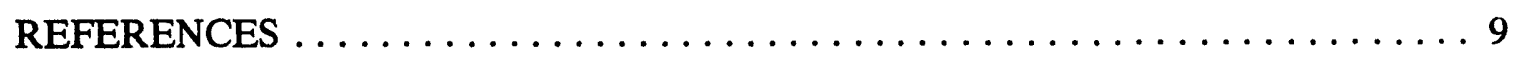




\title{
ANALYSIS OF FEMTOGRAM-SIZED PLUTONIUM SAMPLES
}

D. H. Smith, H. S. McKown, D. T. Bostick, R. M. Coleman,

D. C. Duckworth, and R. L. McPherson

\begin{abstract}
This report describes a study to determine how well isotopic ratios can be measured for very small samples of plutonium. Resin beads were used to simulate particles; for samples ranging from 5-16 fg, collection efficiencies (ions collected per atom loaded) of $4-9 \%$ were obtained. Isotopic ratios with $4 \%$ precision and accuracy (240/239) were obtained.
\end{abstract}




\section{INTRODUCTION}

The goal of this investigation was to extend the ability to perform isotopic analysis of plutonium to samples as small as possible. Plutonium ionizes under thermal ionization conditions about an order of magnitude more efficiently than uranium, primarily due to its lower first ionization potential $(5.7$ vs. $6.2 \mathrm{eV})$. Sub-nanogram sized samples can be analyzed on a near-routine basis given the necessary instrumentation. To achieve the highest sensitivity in thermal ionization mass spectrometry it is necessary to have a single-filament source and a pulse-counting detection system. Single filament thermal ionization produces more ions detected per atoms loaded than do the more common two- or three-filament configurations. The latter, however, yield better precision because of higher signal levels and more stable ion beams. Pulse-counting provides the ability to detect each ion individually as it reaches the detector, and gives 100-1000 times more sensitivity than Faraday cups. Because achieving the highest sensitivity was the focus of this work, both instrumental characteristics were needed.

The Saha-Langmuir equation ${ }^{1}$ governs the production of gas-phase ions relative to gas-phase atoms. It is usually written:

$$
\frac{N_{+}}{N_{0}}=\frac{g_{+}}{g_{0}} e^{(\phi-I) / k T}
$$

where $N_{+} / N_{o}$ is the ratio of charged to neutral species leaving the surface, $g_{+} / g_{o}$ is the ratio of statistical weights of ionic and charged states, $\Phi$ is the work function of the surface, I the ionization potential of the analyte element, $k$ the Boltzmann constaant, and $T$ the temperature in degrees $\mathrm{K}$. The physical situation for which this equation was derived was that of an atomic beam impinging on a hot surface in the absence of a strong electric field. (A strong electric field would perturb the outermost electrons of the incoming atoms and tend to move them closer to the ionization continuum. This situation does not normally obtain in thermal ionization.)Thermodynamic equilibrium was assumed; the number of atoms, $\mathrm{N}$, reaching the surface equaled the number of atomic species leaving it $\left(\mathrm{N}_{+}+\mathrm{N}_{\mathrm{o}}\right)$.

The ratio $\mathrm{g}_{+} / \mathrm{g}_{\mathrm{o}}$ is not usually known for atoms as electronically complex as plutonium's and is assigned a value of 1.0. This estimate is virtually always acceptable, any small deviations from 1.0 being insignificant in comparison to other uncertainties. 
From the Saha-Langmuir equation it is apparent that low ionization potentials and high work functions lead to high ion yields. Although this equation almost certainly doesn't describe the situation for single filament thermal ionization, the critical importance of these two parameters remains. The ionization potential of an element is one of its inherent properties; there is no way to reduce it. There are, on the other hand, ways to increase the work function of the ionizing surface. Previous work revealed that a surface of a rheniumcarbon composite had a work function higher than that of pure polycrystalline rhenium (5.8 vs. $5.4 \mathrm{eV}){ }^{2}$ Rhenium and carbon do not form a stoichiometric compound, but carbon does dissolve in rhenium to an appreciable extent. Early experiments with uranium and other actinides revealed that heating the filament to about $200^{\circ} \mathrm{C}$ below the ionizing temperature in $10^{-5}$ torr benzene vapor enhanced ion emission. ${ }^{3}$ Samples were loaded as dilute nitric acid solutions, an oxidizing environment. At the time ionization improvement was attributed to reduction of oxide species; while this undoubtedly played a major role, the enhanced work function would also have contributed. It is now known that almost any unsaturated hydrocarbon will effect similar improvement; butene has been so used, for example. ${ }^{2}$

Considerations such as these led to an effort to generate more reproducibly the composite $\mathrm{Re}-\mathrm{C}$ surface and at the same time control better the evaporation process. Loading samples on individual anion or cation resin beads offered the possibility of improved performance in both regards. Early work in this area used the beads as both sample collection devices and to enhance ionization characteristics. ${ }^{4}$

A resin bead decomposes when the filament is heated, leaving a carbon skeleton, which serves as a good approximation of a point source for the mass spectrometric ion optics. The carbon residue is a reducing medium for the sample, essentially eliminating emission as undesired oxide species. A secondary ion mass spectrometric investigation revealed that, during analysis, the bulk of the sample remains in the carbon skeleton of the bead, which gradually dissolves in the rhenium substrate; the skeleton thus serves as a sample reservoir, bringing the sample to the ionization region in a manner far better controlled than that attainable when straight solutions are loaded. ${ }^{5}$ The ionization region is the bead-rhenium interface, the only region of the filament with the $\mathrm{Re}-\mathrm{C}$ composite. (Carbon has a work function of about $5.0 \mathrm{eV}^{6}$ and thus contributes little to ion emission.) Use of resin beads was so advantageous for their ion emission characteristics that using them became the preferred method of sample loading in our laboratory. 
One always wishes to do better, however, and a technique that provided even better performance was sought. Perrin and Rokop developed a method that involved electroplating both the sample and a rhenium ${ }^{7}$ or platinum ${ }^{8}$ overlayer onto the rhenium filament. Electroplating, however, was not easily adapted to samples loaded on resin beads. A layer of rhenium powder, slurried with a solution of sucrose (to provide a source of carbon), was added atop the resin bead. ${ }^{9}$ About $3 \mathrm{mg}$ of rhenium was added in $1 \mu \mathrm{L}$ of solution using a micropipette. Upon heating, the powder sintered to form a barrier to evaporation and force analyte species to migrate through it. Significant improvement in ionization efficiency was achieved; $1.7 \%$ of the plutonium atoms on the filament were registered by the detector and $0.5 \%$ of $U$ atoms. These values were 2-5 times better than previously attained. An additional benefit was the virtual elimination of isotopic fractionation. A NIST U500 certified isotopic standard $(235 / 238 \sim 1.0)$ showed no measurable change of ratio after being analyzed six times longer than usual (total time of about two hours). That the sintered powder served as a barrier to evaporation was shown by a time lag of several minutes between setting the filament to operating temperature and reaching stable (and maximum) ion beam intensity.

The work described above was directed primarily at improving precision of isotopic ratio measurements. It seemed, however, that enhanced ion emission should also translate into the ability to analyze smaller samples, and it was decided to investigate the use of a rhenium powder overlayer for analysis of small plutonium samples.

\section{EXPERIMENTAL}

The mass spectrometer used in this work has been previously described. ${ }^{10}$ It is a tandem magnetic sector instrument with a $30-\mathrm{cm}$ central radius of curvature. It is equipped with a pulse-counting detection system; background counting rates are about one count per minute.

Rhenium powder ( $>99.95 \%$ pure) was obtained from Cleveland Refractory Metals, Solon, $\mathrm{OH}$. Anionic resin beads were obtained from BioRad Laboratories (Richmond, CA); they were screened for size before use to select those with diameters between 125 and 200 $\mu \mathrm{m}$. NIST Pu-947 was used as the sample. 


\section{RESULTS AND DISCUSSION}

The rhenium overcoating technique described previously had several deficiencies that impeded easy use. ${ }^{9}$ One was that sucrose was not a desirable source of carbon; it pyrolyzed upon heating, leaving a gummy, non-conducting residue. It was found that a solution of either starch or collodion was an equally effective source of carbon for modifying the work function and did not leave a residue. Both were used in this study.

A second obstacle to easy use of the technique was the tendency of the beads to decompose explosively upon heating. When this occurred after the rhenium overlayer had been added, the rhenium powder overlay was blown away, leaving a pinhole over the location of the bead. Performance in these circumstances was no better than if the powder had not been added. Drying the beads for $8-12$ hours at $103^{\circ} \mathrm{C}$ on the filaments after applying the powder served to eliminate the water, the agent that blew away the powder.

Small particulate samples were simulated by exposing a known number of Dowex $1 \mathrm{X} 2$ resin beads to plutonium solutions at known concentrations. Samples were prepared to provide $0.2,0.02$, and $0.005 \mathrm{pg}$ Pu per bead (Preparations 1, 2, and 3, respectively). The plutonium from several beads from each preparation was desorbed and the amount of $\mathrm{Pu}$ determined by isotope dilution mass spectrometry. A concentration per unit volume of bead was determined for each batch. On the assumption that the beads were evenly loaded with piutonium, knowledge of a bead's diameter allowed calculation of the amount on it.

A good measure of one's ability to measure an isotopic ratio is to determine the ion collection efficiency, defined here as the ratio of ions collected to atoms loaded on the filament. Keep in mind that the best precision to which an intensity can be measured is the square root of the number of counts collected; the less abundant peak in a ratio usually dominates overall precision. For example, if $1 \%$ precision is desired, at least $10^{4}$ counts of the less abundant isotope will have to be collected. Note that, in this case, $1 \%$ is the best precision obtainable; it can be far worse.

The heaviest loaded beads approximated the load used in our earlier work. ${ }^{9}$ One such bead was run to exhaustion and basically duplicated previous results. A number of beads from each of the other preparations were also run to exhaustion. The results are summarized in Table 1. 
Table 1. Collection Efficiency

\begin{tabular}{lccc}
$\underline{\mathrm{Pg} \mathrm{Pu} / \mu^{3}}$ & Atoms ${ }^{239} \mathrm{Pu}$ & Counts ${ }^{239} \mathrm{Pu}$ Collected & Efficiency $(\%)$ \\
$1.2 \times 10^{-8}$ & $2.9 \times 10^{8}$ & $4.9 \times 10^{6}$ & 1.7 \\
$1.8 \times 10^{-9}$ & $3.8 \times 10^{7}$ & $2.9 \times 10^{6}$ & 7.6 \\
$1.8 \times 10^{-9}$ & $3.8 \times 10^{7}$ & $3.6 \times 10^{6}$ & 9.4 \\
$1.8 \times 10^{-9}$ & $2.1 \times 10^{7}$ & $1.9 \times 10^{6}$ & 8.9 \\
$6.3 \times 10^{-10}$ & $1.3 \times 10^{7}$ & $5.6 \times 10^{5}$ & 4.3 \\
\hline
\end{tabular}

A second bead from the third preparation (.002 pg per bead) was run but instrumental instability invalidated the analysis.

The results in Table 1 tend to confirm the previous observation that ionization efficiency increases as sample size decreases. This is probably because a greater fraction of the atoms of small samples come into direct contact with the ionizing surface than is the case with larger samples. The apparent reversal of this trend with the smallest samples (Preparation 3) may be due to the difficulties in locating and focusing the small ion beam produced; ion counting rates for Preparations 2 and 3 were only several hundred counts per second.

In another experiment, the isotopic composition of plutonium was measured using one of the beads from Preparation 2. Equal time was spent measuring each isotope. Mass positions 238 and 241 had inferences from ${ }^{238} \mathrm{U}$ and ${ }^{241} \mathrm{Am}$, respectively, and the ratios involving these isotopes were skewed as a result. Table 2 lists the results of the other ratios, along with the values expected from NIST-947.

Table 2. Isotopic Analysis of $16 \mathrm{fg} \mathrm{Pu}$ in NIST-947

240/239. $\quad \underline{242 / 239}$ Counts 239

$\begin{array}{lll}\text { Ratio } & 0.251 & 0.017 \\ \text { S.D. } & 0.012 & 0.005 \\ \text { Certified } & 0.241 & 0.016\end{array}$


Count rates during analysis ranged from about 200 to about 800 counts per second. Because of these low rates, the results in Table 2 do not approach in precision and accuracy what is routinely obtained with larger samples. On the other hand, reasonable estimates of isotopic abundance were obtained from only about $10^{7}$ atoms.

The question of detection limits is somewhat difficult to address. For the analysis summarized in Table 2, 925 counts of ${ }^{242} \mathrm{Pu}$ were collected out of about 80,000 atoms of ${ }^{242} \mathrm{Pu}$ loaded. This suggests that a crude ratio could be measured from this many atoms of plutonium. The detection limit for ${ }^{239} \mathrm{Pu}$ would be much lower, perhaps a thousand atoms or lower. This would, of course, have to be demonstrated experimentally.

Locating and focusing ion beams from samples this small can be quite challenging. Under circumstances of routine use, it would be desirable to spike the sample to provide an ion beam of reasonable intensity to use for these purposes. Using a plutonium isotope for this purpose, however, would almost certainly compromise isotopic abundance measurements. Even the purest individual plutonium isotopes have enough ${ }^{239} \mathrm{Pu}$ and ${ }^{240} \mathrm{Pu}$ to affect significantly the measured count rates for those isotopes when so few sample atoms are present. Some years ago, when developing a plutonium double spike for internal calibration, the purest isotopes we could find were 99.85 and $98.96 \%$ pure for ${ }^{242} \mathrm{Pu}$ and ${ }^{244} \mathrm{Pu}$, respectively. ${ }^{11}$

A better choice for a beam-locating spike might be natural uranium. Even though uranium ionizes with only about $10 \%$ of the efficiency of plutonium, it should be possible to establish an optimum amount of spike to add. Americium and neptunium are two other possibilities, but these elements are rare, expensive, and more radioactive than uranium. In addition, americium would almost certainly compromise the 241 mass position, and neptunium probably does not offer significant advantages over uranium.

\section{CONCLUSIONS}

The efficacy of emission-enhancing overcoat in the isotopic analysis of plutonium has been demonstrated. Samples as small as about $10^{7}$ atoms were measured with ion collection efficiencies in the 4-9\% range. Reasonable ratios were obtained for those isotopes free of interferences. It thus appears that an overcoat of a rhenium-carbon composite should be evaluated in cases where enhanced emission of metal ions is desired or when the best possible precision is desired. 


\section{REFERENCES}

1. I. Langmuir and K. H. Kingdon, Proc. Royal Soc. (London) 107, 61 (1925).

2. D. H. Smith, J. Chem. Phys. 55, 4152 (1971).

3. A. E. Cameron, Actinides Rev. 1, 299 (1969).

4. D. H. Smith, R. L. Walker, and J. A. Carter, Anal. Chem. 54, 827A (1982).

5. D. H. Smith, W. H. Christie, and R. E. Eby, Int. J. Mass Spectrom. Ion Phys. $\underline{6}$, 301 (1980).

6. CR Handbook of Chemistry and Physics, 64th Edition, R. C. Weast, ed., CRC Press, Boca Raton, FL, 1983, p. E-76.

7. D. J. Rokop, R. E. Perrin, G. W. Knobeloch, V. M. Armijo, and W. R. Shields, Anal. Chem. 54, 957 (1982).

8. R. E. Perrin, G. W. Knobeloch, V. M. Armijo, and D. W. Erfurd, Int. J. Mass Spectrom. Ion Processes 64, 17 (1985).

9. D. H. Smith and J. A. Carter, Int. J. Mass Spectrom. Ion Phys. 40, 211 (1981).

10. D. H. Smith, W. H. Christie, H. S. McKown, R. L. Walker, and G. R. Hertel, Int. J. Mass Spectrom. Ion Phys. 10, 343 (1972-73).

11. D. H. Smith, R. L. Walker, and J. A. Carter, ORNL/TM-9779, Nov. 1985. 


\section{DISTRIBUTION}

1. W. L. Belew

2. J. N. Cooley

3. J. A. Carter

4-8. D. H. Smith

9. D. T. Bostick

10-14. D. C. Duckworth

15. R. M. Coleman

16. R. L. McPherson

17. L. R. Riciputi

18. C. M. Barshick

19. E. H. McBay

20. S. A. McLuckey

21. M. L. Poutsma

22. W. D. Shults

23. Patent Section

24. Laboratory Records

25. Laboratory Records-RC

26. Central Research Library

27. Document Reference Section

28-29. Office of Scientific and Technical Information, P. O. Box 62, Oak Ridge, TN 37830

30. Assistant Manager of Energy Research and Development, Oak Ridge, TN 37830 

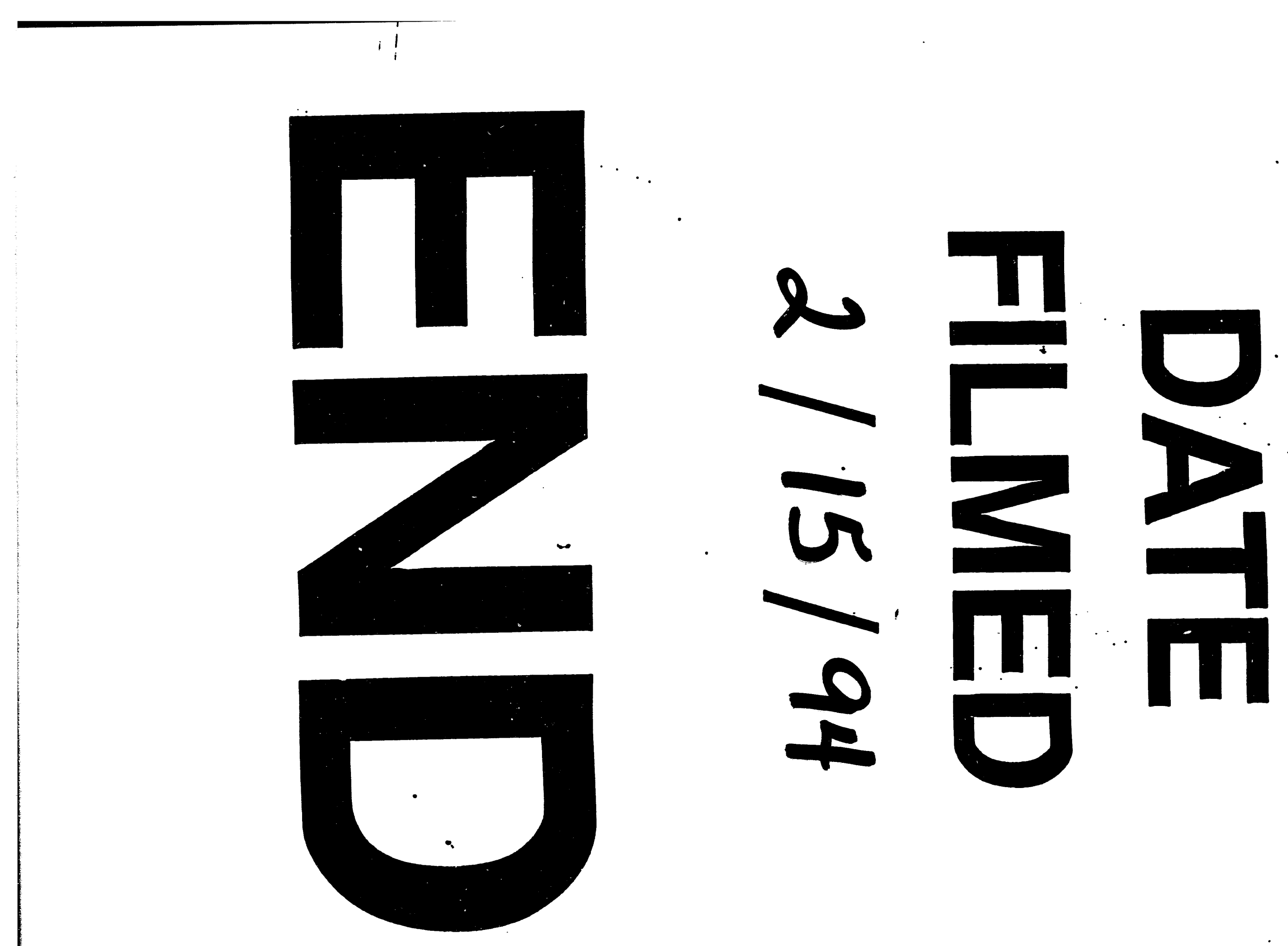


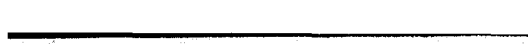

